\title{
Transboundary Conservation Areas in African Mountains: Opportunities and Challenges for Addressing Global Change
}

\author{
Nakileza Bob Roga ${ }^{1, *}$, Wilem Ferguson ${ }^{2}$, Festus Bagoora ${ }^{3}$ \\ ${ }^{1}$ Department of Environmental Management, Makerere University, Mountain Resource Centre, Kampala, Uganda \\ ${ }^{2}$ Centre of Environmental Studies, University of Pretoria, Pretoria, South Africa \\ ${ }^{3}$ National Environment Management Authority, Kampala, Uganda
}

Email address:

nakilezabob@gmail.com (N. B. Roga; http://orcid.org/0000-0002-9718-0460)

*Corresponding author

\section{To cite this article:}

Nakileza Bob Roga, Wilem Ferguson, Festus Bagoora. Transboundary Conservation Areas in African Mountains: Opportunities and Challenges for Addressing Global Change. Earth Sciences. Vol. 6, No. 6, 2017, pp. 117-126. doi: 10.11648/j.earth.20170606.13

Received: July 24, 2017; Accepted: August 21, 2017; Published: October 13, 2017

\begin{abstract}
The last 15 years have seen the establishment of several transboundary conservation areas (TBCAs) in Africa, presenting a unique opportunity of using an integrated ecosystem approach for promoting sustainable ecosystems services. TBCAs have unique characteristics for livelihood improvement of adjacent human communities. Mountain TBCAs in Africa, are increasingly being threatened due to commercial exploitation as well as population and commercial growth, resulting in logging, conflicts and poor land use practices. This is being exacerbated by challenges of climate change. We examined the potential of the TBCA approach for the alleviation of such threats and promoting sustainable mountain development including adaptation and coping mechanisms with respect to climate change. Data and information was gathered largely through field observations, discussions and relevant secondary sources. The results revealed that: 1) While single countries have developed frontier areas within the established TBPAs there is a lack of transboundary governance that enables transboundary development of infrastructure and the sustainable management of natural resources. 2) Socio-economic development and adaptation of human communities towards climate change inside TBPAs have largely taken place as part of activities not connected to the establishment of a TBCA. In conclusion for realising the exceptional opportunities that TBPAs offer, two things are important; 1) To date, biodiversity conservation inside TBPAs has been emphasised. Sustainable livelihood improvement inside a TBPAs should be the point of departure for achieving conservation of natural resources including biodiversity. 2) The establishment of consistent transboundary governance is crucial for achieving that.
\end{abstract}

Keywords: African Mountains, Global Change, Trans-Boundary, Conservation Area

\section{Introduction}

In recent decades mountain environments have witnessed varying shocks and stress resulting from global change among others. Global change is the long term change in environment and ecosystems services due to the way in which humans interact with their environment [1]. It includes environmental effects due to increased human density (e.g. long term soil degradation), as well as long term anthropogenic climate change. This paper adopts a broader perspective of global change but focuses more on the human related interactions in the mountains. Mountain regions are amongst the most sensitive to global change, and receding glaciers are one of the most visible indicators of global change [2]. It is argued that if current trends continue, many glaciers are expected to disappear completely by the end of the century, potentially leading to catastrophic changes in weather and water availability in surrounding regions that rely on mountain ecosystems. Accordingly, [3] notes that the potential for destabilization of human security from global change impacts 
in mountains is particularly high because of the link between potential changes in mountain water supply and 'downstream' populations that rely upon this fundamental resource. [4] observe that many scientists predict changes in mountain shadow effects, storm frequency and intensity, and periodicity in temperature regimes. There are expected increased fire frequency and invasion by insects and other deleterious pest and pathogens that will alter the functioning of and ecosystem services.

Many of the Protected areas [parks and reserves] are established in frontier regions [5] and this result in ecological benefits of larger contiguous protected areas and of shared responsibility; there are also political benefits which promote bilateral understanding and strengthening ties between countries.

In Africa there are a number of mountains with TBCA initiatives. Figure 1 illustrates the spatial distribution of these TBCA areas, which include Virunga Mountains, Maloti-Drakensberg, Kilimanjaro, Nimba Mountains and Mt. Elgon. A summary of their characteristics is provided in Table 1. The TBCA have complexes including national parks, forest reserves, Man and Biosphere Reserve, World Heritage Sites (WHS), and surrounding community lands utilised for grazing or farming.

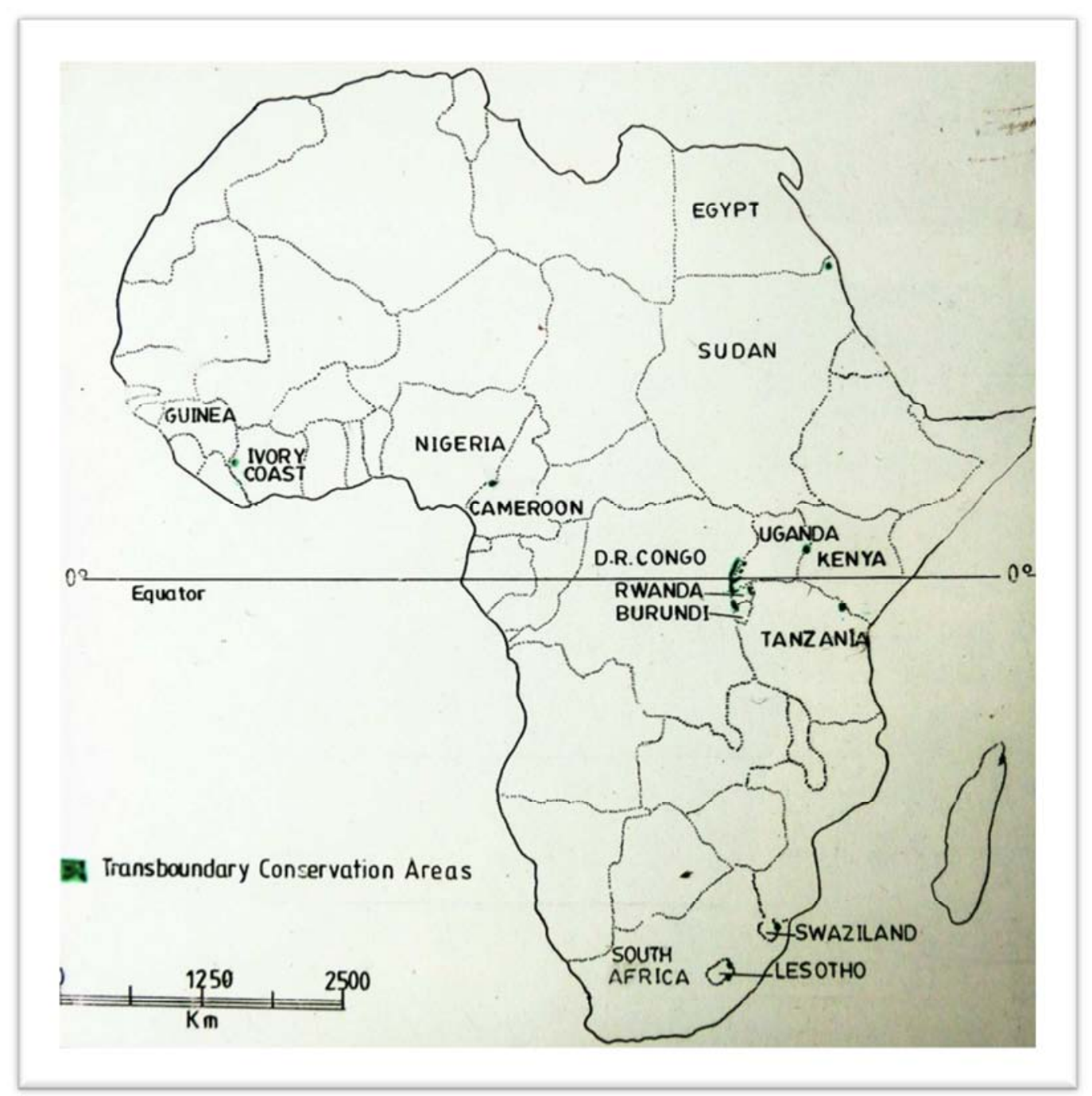

Figure 1. Mountain Transboundary Conservation areas in Africa.

Table 1. The characteristics of TBCA in Africa.

\begin{tabular}{llll}
\hline Mountain[s] & TBCA & Country/Location & Area ha/km \\
\hline \multirow{3}{*}{ Virunga volcanoes } & The Virunga volcanoes [Mgahinga or Gorilla & Rwanda, & 160 \\
& National park, Parc nationale des Virunga \& & Uganda, & 33.7 \\
& Parc national des Volcans] & Democratic republic of Congo & 240 \\
\multirow{2}{*}{ Mt Elgon } & Elgon [ Mt Elgon NP, MAB-BR, Forest & Kenya, & 34,000 ha \\
& reserve] & Uganda & \\
\multirow{2}{*}{ Nimba Mountains } & Nimba [Mt Nimba Mt Nimba strict nature & & 17,540 ha with 12540ha in Guinea, 5,000ha in \\
& reserve (WHS), RUa biosphPre des Monts & Liberia, Guinea, Coute d'lvoire & Cote D'Ivoire \\
\hline
\end{tabular}




\begin{tabular}{|c|c|c|c|}
\hline Mountain[s] & TBCA & Country/Location & Area ha $/ \mathrm{km}^{2}$ \\
\hline Drakensberg & $\begin{array}{l}\text { Maloti-Drakensberg Transfrontier } \\
\text { Conservation and Development Area 2001); it } \\
\text { includes the uKhahlamba Drakensberg World } \\
\text { Heritage Site, Sehlabathebe National Park }\end{array}$ & Lesotho, South Africa & $\begin{array}{l}13000 \mathrm{~km}^{2} \\
\text { The protected areas included are: Ukhahlamba } \\
\text { / Drakensberg Park: World Heritage Site in } \\
2000 \text { ( } 242,813 \text { ha) Golden Gate Highlands } \\
\text { National Park: South Africa ( } 11,600 \text { ha) } \\
\text { Sehlabathebe National Park: Lesotho ( } 6,500 \\
\text { ha) Ts'ehlanyane Nature Reserve: Lesotho } \\
(56,000 \text { ha) Bokong Nature Reserve: Lesotho } \\
(1,970 \text { ha) }\end{array}$ \\
\hline Lubombo & $\begin{array}{l}\text { Lubombo Transfrontier Resoure and } \\
\text { Conservation Area (2000); Includes most of } \\
\text { the Lubombo Mountains. }\end{array}$ & $\begin{array}{l}\text { Moçambique, South Africa, } \\
\text { Swaziland. }\end{array}$ & $\begin{array}{l}\text { Maputo Special Elephant Reserve, Royal } \\
\text { Swazi Hunting Grounds, Ndumu Game } \\
\text { Reserve, Tembe Elephant Park. }\end{array}$ \\
\hline Kilimanjaro & $\begin{array}{l}\text { Kilimanjaro National park, [WHS] } \\
\text { Amboseli National Park [MAB-R] }\end{array}$ & $\begin{array}{l}\text { Tanzania, } \\
\text { Kenya }\end{array}$ & \\
\hline Gebel Elba & $\begin{array}{l}\text { Elba-Nibia Transboundary Park. Sometimes } \\
\text { simply called Egypt-Sudan Transboundary } \\
\text { park. }\end{array}$ & Egypt, Sudan & $\begin{array}{l}\text { Gabal Elba national park } 3,560,000 \text { ha. It also } \\
\text { includes Wadi Allaqi Biosphere reserve in } \\
\text { Egypt. }\end{array}$ \\
\hline
\end{tabular}

\section{Transboundary Conservation Paradigm}

There is no universal definition of transboundary conservation approach in the world. Many concepts relating to transboundary frameworks (e.g. TBNRM, TBPA, TBCA, TFCA) exist but all entail the sustainable use of natural resources as a means for increased economic development by way of multi-scale and multi-actor networks [6]. Co-management is one of the most distinctive elements and prerequisites of all transboundary conservation areas in comparison to protected areas of non-transboundary character. In this paper we adopt an all inclusive perspective of trans-boundary conservation [protected areas, reserves, or other landuse].

Transboundary conservation is not new in African mountains. It is reported that by the time the 1900 Convention [Convention for the Preservation of Wild Animals, Birds and Fish in Africa] was agreed to, an early form of transborder conservation had already begun in the Virunga Mountains, where Belgium established Africa's first national park in 1925. In 1929, the Belgian authorities expanded Albert National Park to include all of the Virunga Mountains that traversed the two colonies of the Belgian Congo and Ruanda-Urundi. This expansion laid the foundation for an incipient transborder park, for when the colonies gained their independence in the 1960s, the park was split into the Virunga National Park of the Democratic Republic of the Congo (Zaire 1971-1997) and Volcanos National Park of Rwanda. Although transborder conservation initiatives in the region have been stymied by civil wars on both sides of the border, in October 2005 the three countries [DRC, Rwanda and Uganda] signed a Tripartite Declaration that recognized the need to establish a "Central Albertine Rift Transfrontier Protected Area Network."

With so many TBPAs worldwide, conservationists have devised several ways of categorizing them. One group of conservation practitioners, for instance, has delineated five different types of TBPAs on the basis of geographic parameters: (a). two or more contiguous protected areas across a national boundary;

(b). a cluster of protected areas and the intervening land;

(c). a cluster of separated protected areas without intervening land;

(d). a transborder area including proposed protected areas; and

(e). a protected area in one country aided by sympathetic land use over the border.

A number of transboundary conservation areas [e.g. Virunga, Rwenzori, Kilimanjaro, Maloti-Drakensberg] in Africa entail protected areas stretching across their common border or a cluster of protected areas with intervening land under various uses such as grazing and farming (Figure 2).

Another group of conservationists identified three different ways that "transboundary initiatives develop." First, high-level initiatives involve officials within an administrative capacity above the level of direct land management. Second, locally based initiatives refer to those established at the level of direct "on-the-ground" land management. Finally, third-party initiatives occur "via a conservation non-governmental organisation (NGO) acting as a third party advocate, encouraging and supporting co-operative transboundary management." The developments of transboundary conservation areas in Africa have involved a mix of the above but important to recognise is the persistent driving role of NGOs and the local managers across the national borders.

One type of transboundary protected area (TBPA) is the "Peace Parks", which is defined as: "An area of land and/or sea that straddles one or more boundaries between states, sub-national units such as provinces and regions, autonomous areas and/or areas beyond the limits of national sovereignty or jurisdiction, whose constituent parts are especially dedicated to the protection and maintenance of biological diversity, and of natural and associated cultural resources, and managed co-operatively through legal or other effective means" [7].

The debate on the potential benefits and also detrimental effects brought about by Transboundary initiatives is not conclusive. Positive arguments include fostering peace and security, promoting economic development though tourism, 
biodiversity conservation, environmental security and enhanced regional cooperation among others. However, one of the negative effects includes escalated land conflicts in cases where conservation restricts access to traditional resources. [8] argued that engaging in TBPAM-cooperation often accrues additional transaction costs, is challenged by forces of vertical and horizontal interplay, and puts increased constraints on the often already weak Protected Area authorities.
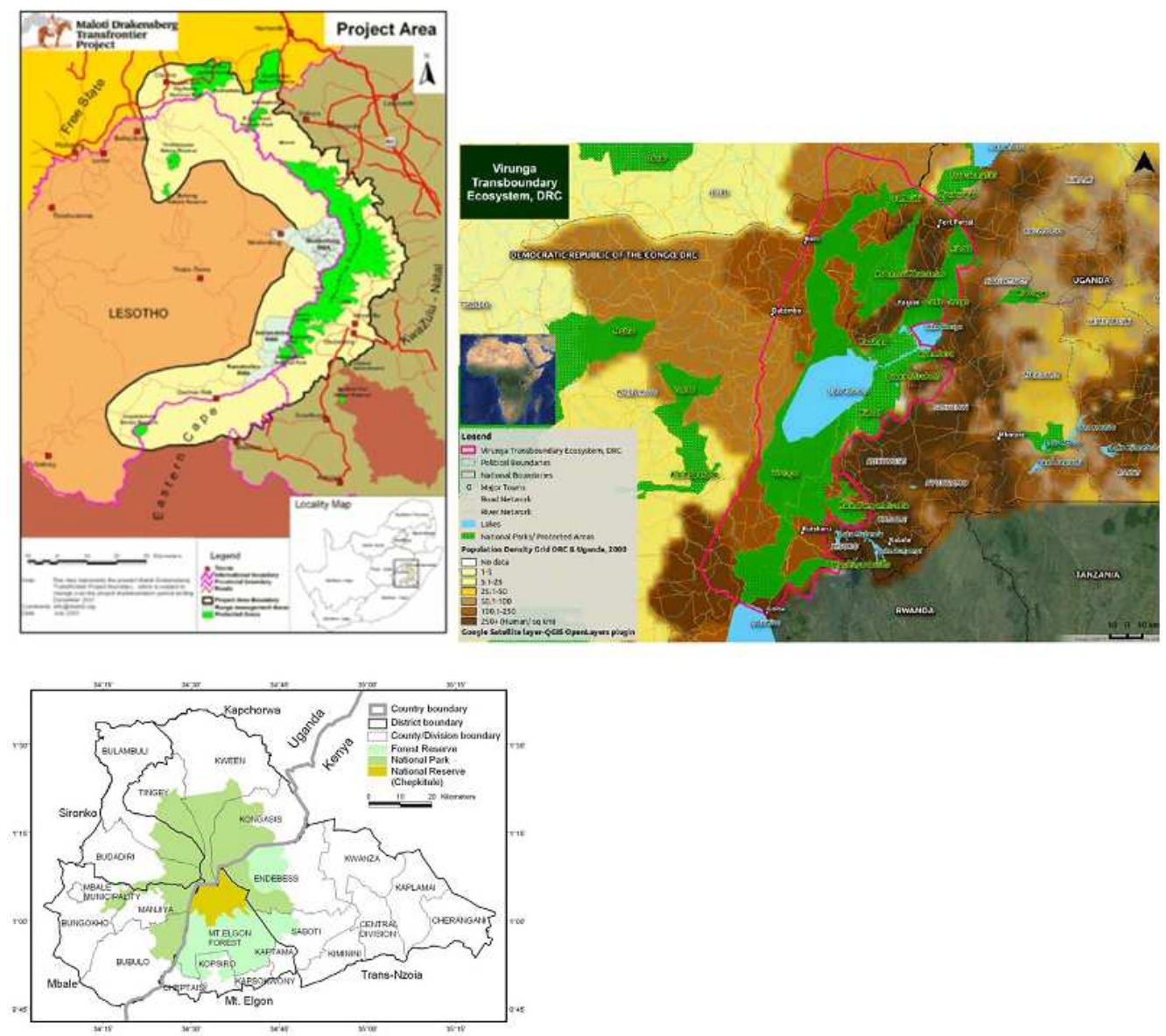

Figure 2. Typology of the transboundary conservation areas in Africa; left is the Maloti-Drakensberg TCA; right is the Virunga landscape [7]. Lower is Mt Elgon $T C A$.

This paper aims at (1) examining the opportunities presented by the TBCAs and (2) analysis of threats to these conservation areas in Africa. In view of the threats, the paper advances suggestions for improved conservation and realization of the benefits of TBCAs.

\section{Methods}

A case study approach was applied covering the main TBCAs in Africa namely the Maloti-Drakensberg and Lubombo in Southern Africa, and Mount Elgon and Mgahinga in Eastern Africa. The study is largely based on qualitative data. Data on opportunities, governance and adaptation were mainly gathered through a critical review of the existing secondary sources, extensive interviews and discussion with pertinent TBCA officials in the respective study mountain areas. Personal researcher observations and experiences were also found useful in supplementing other data sources. Secondary sources reviewed included TBCA reports, grey literature and journal publications. Limited face to face discussions were held with relevant officials working in the field with TBCAs to obtain their views on existing opportunities, threats and challenges.

\section{Results and Discussion}

\subsection{The Opportunities Offered by Transboundary Protected Areas}

\subsubsection{Improved Sustainability of Ecosystem Services}

Depending on the characteristics of a mountain TBPA, the ecosystems services affected are mostly water and biodiversity. The establishment of a TBPA improves water provision, especially in mountain areas [9]. The establishment of peace parks focus on the conservation or sustainable use of biodiversity [5]. The conservation of soil is also promoted by the establishment of a TBPA. Clearly, the sustainability of the ecosystems services provided by these resources is promoted. In cases where human communities live within a TBPA, the emphasis on and proximity of conservation areas promote the sustainable management of natural resources and the ecosystems services provided to these communities [10]. 


\subsubsection{Improved and Consistent Regional Governance}

Peaceful coexistence and cooperation is a core purpose of the peace parks concept [11]. Since the majority of military conflict in Africa is in transboundary areas, it stands to reason that the possibility of such conflict is ameliorated by TBPAs. The consistent application of local legislation and regulations in all partner counties involving a TBPA promotes the stability of human communities and reduces the possibility of cross-boundary trafficking. In the Lubombo TBPA, one of the key issues is the stabilisation of cross-boundary criminal acts. The pressure for this stability would be reduced or absent without a TBPA. In Mt Elgon and Virunga, the crossborder armed conflicts have been mitigated by the transboundary cooperation.

\subsubsection{Improved Livelihoods for Local Human Communities}

In TBPAs that include human communities, the establishment of a TBPA often has a goal of promoting sustainable livelihoods. For instance, the Mozambican minister of environmental affairs declared that the Lubombo TBPA "is not just about conservation. Its name indicates that it is also about development.... It is another step along the way to the realisation of our dream of a prosperous Lubombo region capable of providing a life of dignity to all its people." [12]. Improved employment, investment, tourism and ecoagricultural approaches are clearly-defined objectives of TBPAs.

\subsubsection{Improved Adaptability Towards Environmental Change}

The above three opportunities promote the adaptation of TBPA-based human communities towards environmental change, a critical requirement for sustainable livelihoods. This includes both the effects of global climate change and local management of natural resources [13].

\subsection{Threats to Trans-Boundary Protection Areas}

Mountain ecosystems and mountain TBPAs in Africa are threatened in many ways, among others those relating to changes in land use and climate. Global threats include changes that are global in nature/origin and perspective e.g. climate change, marketing of mountain resources [e.g. water, tourism] and products for export [e.g. coffee, minerals]. On the other hand, local threats are site specific, national and regional. Most of the threats to mountain TBPAs directly mirror the opportunities outlined above.

\subsubsection{Local Threats, Mostly Through Nonsustainable Land Use and Human Need}

Nonsustainable use of natural resources due to poverty or exploitation of natural resources. For instance, on the Kenyan side of Mount Elgon, clearing of forests has taken place due to the increasing pressure for the needs of local communities. Commercial timber companies such as RaiPly have had a significant impact on the forests. Particularly the indigenous tree species such as Olea campesis has been severely reduced. On the Uganda side of Mt Elgon serious encroachment has been fueled by political motives and demands for access to land in forests for agriculture purposes [14]; [15]; [16]. On Mount Kenya, poachers have set the vegetation alight to drive out game, burning large areas in the process. In the Lubombo, one of the local communities has destroyed part of the game fencing of the Ndumo Reserve inside the TBPA and have settled inside this reserve.

Crossborder military conflict or crossborder criminality [17] are important destabilisation factors for mountain TBPAs. In the Maloti-Drakensberg, armed traffickers of marijuana from Lesotho make many areas unsafe to enter. In the Lubombo, trafficking of arms and animal products to and from Moçambique has created acute local instability within this TBPA. The periodic tense crossborder relationships between Uganda and the DRC have resulted in military action in the Rwenzori. Armed conflicts have also affected the Mt Elgon area in both Kenya and Uganda. The root causes are social-political stretching way back in the colonial era. For instance, the Saboat of Mt Elgon district in Kenya put up an armed rebellion in late 1990s in an attempt to secure land rights but other political motives were noted [18]. Small ammunitions were smuggled across borders thus heightening the conflict that left many dead, injured or displaced. Up to today tensions are still high is some places. It is important to note that conflicts usually draw attention away from long-term conservation and development objectives to short-term objectives related to the political and security situation [19].

\subsubsection{Global Threats, Mostly Through Climate Change and International Commercial Exploitation}

A number of African tropical mountain glaciers are receding at a fast rate. For instance, the icecap on Mount Kilimanjaro has almost disappeared largely due to climate change with serious implications for the rivers that depend on ice melt for their flow. A reduction in the Kilimanjaro ice cap of around 82 percent has been observed since it was first surveyed in 1912. Several rivers are already drying out in the summer region due to reduced precipitation, depletion in melt water [20, [21]. Recent projections suggest that if the recession continues at its present rate the ice cap may disappear completely within 15 years. Precipitation in the Kilimanjaro has reduced by $\sim 30 \%$ that is $400-1000 \mathrm{~mm}$ per annum [22]. In the Virunga TBCA change in climate has been observed and projections 2030 point to the decrease in rainfall and increase in temperature which may negatively impact on conservation activities including gorillas [23]. Further south, the Lubombo TBPA includes the area in southern Africa with the most pronounced reduction in rainfall over the last 50 years [24], strongly affecting local food production practices [25].

The commercial exploitation of mountain areas for the international trade has had important consequences in some cases. On Kilimanjaro, the commercial planting of arabica coffee over large areas of the slopes of this mountain has resulted in significant deforestation. Timber exploitation for local use and export from Mt Elgon forests in Kenya and Uganda has resulted in biodiversity loss. Open deforested areas in the park are encroached on for grazing causing 
ecosystem degradation [18].

these have had are summarized in Table 2.

Key threats to African TBPAs, as well as the effects that

Table 2. Environmental threats to TBCA in Africa.

\begin{tabular}{|c|c|c|}
\hline TBCA & Threats & Effects \\
\hline Virunga & $\begin{array}{l}\text { Climate change, Habitat destruction, Poaching, population pressure, } \\
\text { uncontrolled fires }\end{array}$ & Loss of biodiversity, resource scarcity \\
\hline Kilimanjaro & $\begin{array}{l}\text { Poaching, intensive landuse, population pressure, fires, climate change, } \\
\text { glacial retreat }\end{array}$ & $\begin{array}{l}\text { Soil degradation, resource scarcity, reduced water flow, } \\
\text { water resource conflicts, and human-wildlife conflicts }\end{array}$ \\
\hline Rwenzori & $\begin{array}{l}\text { Climate change, Biodiversity loss [poaching, habitat destruction], glacial } \\
\text { retreat, increasing population, landslides, fires }\end{array}$ & Reduced water flows and Resource use conflicts \\
\hline Maloti-Drakensberg & $\begin{array}{l}\text { Climate change, Erosion, water scarcity, excessive livestock grazing, } \\
\text { crop cultivation on steep slopes, uncontrolled burning, alien invading } \\
\text { species and human encroachment threatens. }\end{array}$ & Resource use conflicts and loss of species \\
\hline Lubombo & Climate change, Habitat destruction, population pressure & Water resource conflicts, reduced yields. \\
\hline Elgon & $\begin{array}{l}\text { Encroachment, poaching [including across the border], political } \\
\text { interference, land degradation [soil loss, decline in soil quality, } \\
\text { landslides], climate change, population pressure, moorland/forest fires }\end{array}$ & $\begin{array}{l}\text { Resource scarcity, resource conflicts, reduced resource } \\
\text { base, reduced yields, escalated human-park conflict }\end{array}$ \\
\hline
\end{tabular}

\subsection{The Success of TBPAs in African Mountains}

How successful have TBPAs been in realising the opportunities and in countering or evading the threats discussed above? In order to make an assessment, extensive interviews were conducted with managers of four TBPAs (Maloti-Drakensberg, Lubombo, Mount Elgon and Mgahinga). The interviews focused on achievements with respect to opportunities and threats of their respective TBPAs. A sharp distinction was maintained between achievements, on the one hand, strictly due to the establishment of the TBPA and, on the other hand, due to other regional or international initiatives.

\subsubsection{Regional Transboundary Development Policy and Implementation}

The launch of the Maloti-Drakensberg and Lubombo TBPAs were greeted with great enthusiasm, mostly because sufficient support has been drummed up beforehand and because particular individual politicians and administrators act as champions for the project. However, as these individuals move on and are replaced by others, this support diminishes considerably and the momentum is largely lost. The sustainability of the institutional and administrative support for the TBCA is therefore a major factor that has limited the progress within these two southern African areas. Apart from commitment, large differences in the abilities of two neighbouring countries to become involved in development projects differ. For instance, there has been extremely little biodiversity and tourism development of the Lesotho side of the Maloti-Drakensberg TBPA, whereas the South African side has seen extensive development, mostly due to developments before the establishment of that TBPA. The same applies to the Lubombo TBPA, involving South Africa and Moçambique. The two southern African mountain TBPAs are characterised by a total lack of transfrontier development initiatives, the existing implementations being those of individual countries within their own borders. In eastern Africa, relative progress has been made for Virunga and Mt Elgon transboundary conservation areas. The wildlife conservation authorities of the three countries of the Central Albertine Rift (Institut Congolais pour la Conservation de la
Nature - ICCN in the DRC; the Rwanda Development Board RDB in Rwanda; and Uganda Wildlife Authority - UWA in Uganda) together formed the Greater Virunga Transboundary Core Secretariat (TCS) in 2006 [23]. This has marked greater cooperation in the management of the transboundary conservation area. The Transboundary Conservation Systems provides a platform for constructive engagement across borders and is positioned to build on long-standing landscape management planning efforts that have been developed under the Congo Basin Forest Partnership. Transboundary collaboration within and outside of park boundaries has helped to build trust amongst government officials, park managers and staff, NGOs (conservation, development and humanitarian, etc.), research and academic institutions, and communities, allowing for improved mountain gorilla conservation, forest resource management and sustainable development [23]. The transboundary collaboration approach in the Virunga-Bwindi landscape has resulted in a number of notable achievements [e.g. the ranger monitoring programme] that can be attributed to the collective efforts of regional partners, and as a result of progressive regional processes leading to the creation of the Transboundary Strategic Plan in 2006. IGCP is supporting the development of a regional mountain gorilla conservation policy through transboundary collaboration between the three mountain gorilla range states while working with local communities to reduce their dependence on park resources, minimizing human-gorilla conflicts and supporting a more equitable distribution of the benefits from gorilla tourism. In Mt Elgon, MERECP was designed to address the conservation and development needs of the Mount Elgon ecosystem, among others. It adds value to national conservation and development activities as well as achievements of the recently concluded Integrated Conservation and Development Projects (ICDPs) on both sides of the Mountain to address issues that require a regional approach and efforts. MERECP links environmental management to livelihood security and poverty alleviation, which are priorities for the Governments of Uganda and Kenya. The Programme addresses pressures currently being put on Mount Elgon ecosystem by enhancing natural 
resources productivity, provision of livelihoods options and adding value to natural resources. Further MERECP strengthens institutional capacities, policy and legal frameworks for enabling conservation and sustainable development in a transboundary context, because it is a shared ecosystem between Kenya and Uganda [26]. Conclusion: The ideals as formulated in the signing of the international protocols have therefore not been translated into co-ordinated transboundary initiatives at the political level [14].

\subsubsection{Regional Political and Social Stability}

Both the Maloti-Drakensberg and the Lubombo areas have been affected by illegal cross-border trafficking, ranging from drugs to arms and rhino horns and other wildlife products. In the case of the Maloti-Drakensberg, there have been bilateral international teams that have worked to combat this criminality. However, this has not been the result of the establishment of the TBPA. In the Lubombo, transboundary criminality is endemic in at least one area (Bigabantu), representing a direct threat to any development in the area. The Maloti-Drakensberg and Lubombo TBPAs have not by themselves contributed towards solving this instability. Conclusion: The TBPAs have not been successful in promoting regional political and social stability [26], [27].

\subsubsection{Water Provision}

The Maloti-Drakensberg is the water tower of southern Africa, with South Africa being heavily dependent on Lesotho. The upper catchments are generally in good condition, but many mid to lower catchment areas are degraded and eroded [28]. There have been several catchment improvement initiatives on the South African side, they were not directly related to the existence of the TBPA and there have been no bilateral initiatives. The montane Lubombo area has a chronic shortage of water, especially on the eastern slopes of the mountains. This is a limiting factor for the number of people that can inhabit this area. The local and central governments have been supplying water boreholes with pumps. However, this is part of the regional development plan, and not specifically because of the TBCA. Conclusion: The TBPAs have, in themselves, not been successful in improving existing water provision.

\subsubsection{Soil Conservation}

Overgrazing has been a long standing problem in the southern African TBPAs, especially the Maloti-Drakensberg [29]. Research into the establishment in ecoagriculture has been initiated in the Lubombo, but this has not resulted in any tangible changes yet. Soil degradation through soil loss and nutrient depletion are common in Mt Elgon, Mt Kilimanjaro and the Virungas. Efforts in soil conservation have been initiated and implemented by NGOs (e.g. DTC in Bwindi and Kabale, AHI and IUCN in Mt Elgon) in collaboration with government departments. The Mt. Elgon Conservation and Development programme that has been operating on the Uganda side since 1987 has often been commended for its important role in conserving the ecosystem values of the region. Various reviews in 1993, 1998 and 1999 have all commented positively on the importance of conservation in this region [30]. Soil management activities in selected places by MERECP, a crossborder regional project, were started recently. Conclusion: The TBPAs have not resulted in improved soil conservation yet.

\subsubsection{Biodiversity Conservation}

In southern Africa, bad management of the mountains has resulted in changes in montane biodiversity. Invasive plants and erosion have altered many areas. In the Lubombo there has been large scale transformation of the vegetation from mostly grassland to a closed woodland, probably due to climate change. Grassland biodiversity is assumed to have been affected, especially in a biodiversity hotspot such as the Lubombo. There have been several awareness programmes, as a result of which several community conservation areas (CCAs) exceeding $50000 \mathrm{Ha}$ in size have been established on the South African sides of the Maloti-Drakensberg [31] and the Lubombo. However, several of these were established under existing stewardship programmes, not specifically under the TBPAs. These initiatives have resulted in much greater awareness of biodiversity issues within TBPAs. The Maloti-Drakensberg TBPA has facilitated the establishment of a world heritage site with the same name. In east Africa, all the transboundary ecosystems have suffered degradation caused by encroachment on protected areas, and poor resource management. Conservation efforts by different organisations such as IUCN, WWF, AWF, Face Foundation among others have contributed to restoration of the degraded areas in and outside the parks or forest reserves. MERECP has assisted in boundary park management and creating awareness among the communities in Mt Elgon. Conclusion: Due to the interaction of TBPAs with other existing initiatives, a largely increased awareness of biodiversity issues has been achieved and a number of CCAs were established, thus promoting biodiversity conservation.

\subsubsection{Mitigation of Natural Disasters}

In montane areas, flooding and fires are agents for significant natural disasters that cause deaths and damage to infrastructure and property. In the Maloti-Drakensberg, there is a bilateral safety and security strategy that includes natural disasters. However, this is independent of the TBPA. Conclusion: The TBPAs in themselves have not resulted in improved mitigation of natural disasters.

\subsubsection{Livelihood Improvement}

In South Africa, the extensive dependence of rural families on government grants for child support and for pensions support has largely impeded community initiatives for livelihood improvement. Child support grants actively promotes the birth rate and threatens the sustainability of TBPAs that include rural communities, including the Maloti-Drakensberg and the Lubombo [32]. However, due to the awareness programs associated with the TBPAs, there is much more awareness of income, food security, safety and natural resources. This has not yet resulted in observable livelihood improvement. Conclusion: Although TBPAs have 
contributed to local awareness about livelihood issues, this still needs to be translated into effective development initiatives.

\subsubsection{Effect of Climate Change}

In East Africa, the ice caps and the seasonal sustainability of water supply has been strongly affected by climate change. Glacial water reservoirs on the peaks of Rwenzori and Mount Kenya are facing serious threats [33] [34], which are largely attributed to raising air temperatures and reduced humidity including rainfall. In the Lubombo, vegetation change over a period of 70 years has reduced grazing space for cattle. The area has suffered a significant reduction in rainfall over the last 40 years and there have been several drought years during the last 2 decades. This affects food production and livelihoods. The importance of the Maloti-Drakensberg for water supply has raised the national profile of that TBPA. Conclusion: As would be expected, climate change imposes several challenges on the sustainability of TBPAs, ranging from natural resource provision to livelihoods.

\subsubsection{Adaptability of Communities to Environmental Change}

Table 3 indicates that several agencies are involved in promoting adaptation to environmental change, also in TBPAs. These include:

(a) Tree integration in crop farming- planting of indigenous trees for provision of various ecosystem services [e.g. food, shade, stabilising soils]. This is especially common in the coffee-banana system amongst the Chagga in Mt Kilimanjaro, and the Gishu on Mt Elgon.

(b) Land use manipulation- changes in farm location, abandoning land to allow it stabilise or regain fertility and including shifting times for planting.

(c) Diversifying livelihoods- e.g. small off-farming business, bee keeping, causal labour amongst others.

(d) Adaptation measures to water stress include innovative water resource management. For instance, micro-irrigation of high value crops and water harvesting and storage is increasingly practised on the slopes of Mt Kilimanjaro and Mt Elgon.

(e) Sustainable land management and soil water conservation practices- (e.g. grass bunds, terracing etc); crop diversification, zero grazing, which also yields biogas that lessens pressure on forests.

(f) Decentralisation of local resource governance e.g. at district and community based natural resource management (CBNRM).

(g) Socio-networks; traditionally many mountain people share information, food resources and assist one another in different ways during difficult times.

(h) Migration to other presumed safe areas within or outside the mountain area; especially observed in Kigezi highlands, which is part of the Virunga landscape.

However, none of these initiatives were initiated because of the existence of one or more TBPAs. Conclusion: Therefore, the ability of TBPAs in promoting the adaptability of local communities towards environmental change is questionable.

Overall conclusion for this section: The above points indicate that TBPAs have largely not been conducive towards the high ideals that were articulated when they were initiated. Although local communities have largely acquired a much deeper awareness of environmental issues, this was not translated into alternative practices that promote greater sustainability of livelihoods. Some improvement in biodiversity conservation has been made in the TBPAs that we discussed above. However, the majority of development in these TBPAs and the promotion of adaptation of communities towards environmental change largely resulted from other initiatives that are independent of the existence of any TBPA. The success of the TBPA concept in these cases is therefore in question and a consideration of the future of this concept is required.

Table 3. A summary of adaptation initiatives in different transboundary mountain ecosystems in Africa.

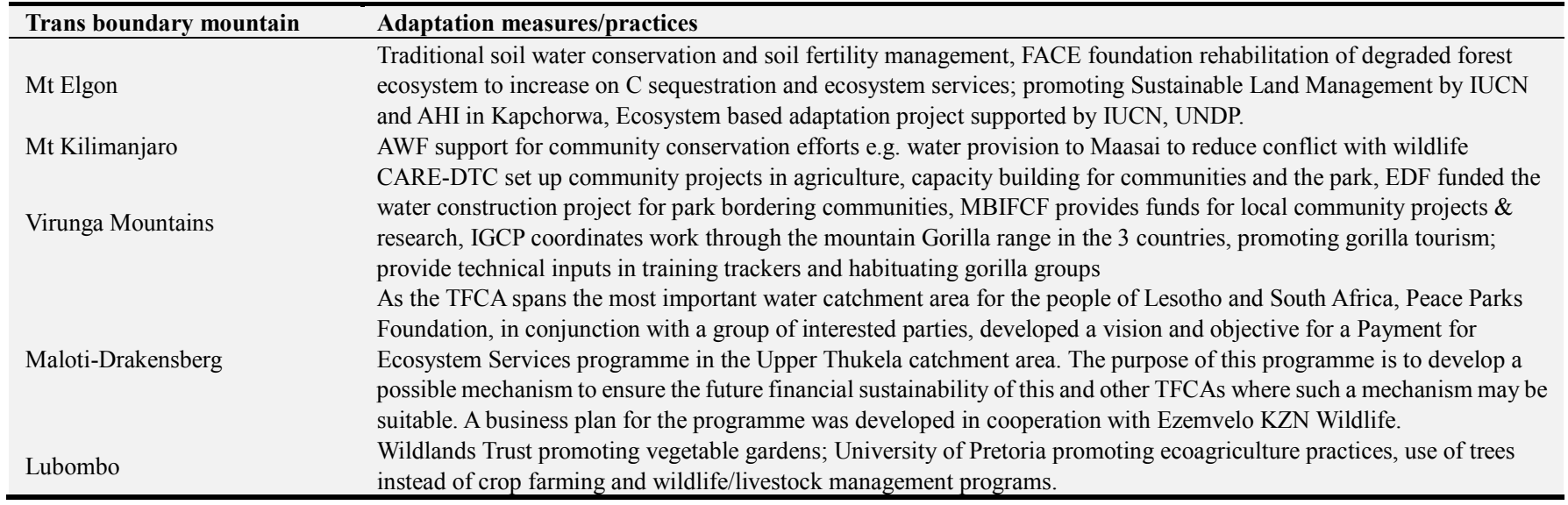

\subsection{The Road Forward for TBPAs in Africa}

\subsubsection{Transboundary Governance}

In order for TBPAs to function as intended, the governance mechanisms need to be in place to promote transboundary interaction. International protocols involved in the founding of TBPAs need to result in local governance that enables local transboundary interaction, the movement of tourists and commodities and the development of co-operative initiatives 
between communities on both sides of a frontier. This is impeded if one country perceives that it is much weaker or poorer than its other partner(s), as is the case between Lesotho and South Africa. At a national level, the large disconnect between local government and tribal authorities in South Africa obfuscated the assignment of responsibilities at the community level and impedes the development of the Maloti-Drakensberg and the Lubombo TBPAs. The lack of a crossborder development policy by both the Uganda and DRC governments impedes the development of the Rwenzori area. East Africa has the East Africa Community protocol on Natural Resource Management that also includes the transboundary mountains. For instance, this has aided the design and operation of the MERECP project [2007-2015] on Mt Elgon, a promising initiative focused on the collaborative management of the ecosystem on Mount Elgon [30]. To achieve greater success in this horizontal and vertical institutional governance challenges noted by [8] will have to be overcome.

\subsubsection{Transboundary Development}

The creation of these TBCA's was accompanied by a large emphasis on the conservation aspect, and not a strong emphasis on the local development/livelihood aspect. This has maintained, and in some cases even intensified, the dichotomy between nature conservation and the livelihoods of local communities. If the lives of human communities within TBPAs are not positively affected, the TBPAs will not be sustainable. Transboundary governance needs to result in regional development. None of the mountain TBPAs that we investigated have any crossborder infrastructure such as roads, easy communication and access to resources such as water. Even though Uganda sells hydro-electricity from Rwenzori to the DRC, the local communities do not perceive that they benefit from this. The implementation of transboundary development programmes (enabled by transboundary governance) is dependent on a strong commitment from all governments involved. International aid agencies should consider such commitment as a requirement for all development projects in or near TBPAs.

\subsubsection{Redesigning the TBPA Concept}

As indicated above, the founding of TBPAs has largely been based on biodiversity conservation grounds. The track record of the TBPAs that we studied suggests that this is not a viable approach and that the fragile mountain ecosystems dependent on them have not greatly benefited. A more viable approach is possibly to focus on the ecosystems services produced in these mountain regions, with much more emphasis on those services from water, soil and (in the third place) biodiversity. There are many precedents worldwide where water provision has been compensated through payment-for-ecosystems-services systems (PES). Currently the idea of environmental certification of communities is being researched, combined with the exploration of new supply chains for products emanating from these communities. Without livelihood improvement, there is unlikely to be sustainable biodiversity conservation. Livelihood improvement is the starting point, not the end point of implementing a TBPA.

\section{Conclusion}

Is the TBCA concept flawed? Despite the fact that several TBCAs have existed for longer than a decade, they do not have much to show in terms of achievement. We argue that the development of a TBCA is a long term undertaking, even if all factors are ideal for a particular area. This task is made even more difficult, given the environmental changes resulting from global change. Livelihood improvement itself is a long term process, not easily realised in many countries as a whole. TBCAs are areas where more factors than usual are in place to support livelihood improvement. For that reason, in TBCAs, governments and nongovernmental organisations have a larger probability than elsewhere of being successful in promoting both sustainability and livelihoods. These opportunities need to be grasped in order to promote adaptability of communities in the face of global change.

\section{Acknowledgements}

The technical support from the Universities of Pretoria and Makerere and the Mountain Research Initiatives for facilitating the research process and participation in the Global Mountain conference in London that provided important enrichment to the paper. Contribution from the respective mountain conservationists is highly appreciated.

\section{References}

[1] National Academy of Sciences, 2000. Global change Ecosystems Research. http://www.nap.edu/catalog/9983.html.

[2] IISD, (2011). Mountain Day Bulletin, 194 (1). http://www.iisd.ca/climate/cop17/md/html/ymbvol194numle. html

[3] IHDP (2002). Transboundary PA http://www.eoearth.org/article/Transboundary_protected_areas IHDP, (2002). Newsletter.

[4] Peine J. D \& Martinka C. J. Impacts of Climate Change on Mountain Protected Areas: Implications for management. $\mathrm{P}$ 55-75. In Pernetta, J. C.; Leemans, R.; Elder, D. \& Humphrey, S. (Eds). 1994. Impacts of Climate Change on Ecosystems and Species: Implications for Protected Areas. IUCN, Gland, Switzerland. viii+ $104 \mathrm{pp}$.

[5] Thorsell, J. (1990): Parks on the Borderline: Experience in Transfrontier Conservation. - IUCN Publication Services, Cambridge (UK).

[6] Jones, J. L. 2010. Transboundary conservation in Southern Africa: Exploring conflict between local resource access and conservation.

http://www.milleniumassessment.org/dcouments/bridging/pap ers/jones.jennifer.pdf

[7] Vasilijević, M., Zunckel, K., McKinney, M., Erg, B., Schoon, M., Rosen Michel, T. (2015). Transboundary Conservation: A systematic and integrated approach. Best Practice Protected Area Guidelines Series No. 23, Gland, Switzerland: IUCN. xii +107 pp. 
[8] Petursson, J. G., P. Vedeld, \& A. Vatn (2013). Going transboundary? An institutional analysis of transboundary protected area management challenges at Mt Elgon, East Africa. $\begin{array}{llll}\text { Ecology and } & \text { Society }\end{array}$ http://dx.doi.org/10.5751/ES-05729-180428.

[9] Messerli B, Viviroli D. \& Weingartner R. 2004. Mountains of the World: Vulnerable Water Towers for the 21st Century. AMBIO. spec. report No. 13, Royal Swedish Academy of Sciences, Stockholm: $29-34$.

[10] Smith R. J., J. Easton; B. A. Nhancale et al. (2008). Designing a transfrontier conservation landscape for the Maputaland centre of endemism using biodiversity, economic and threat data. Biological Conservation 141: 2127-2138.

[11] Sandwith, T. S., Shine, C., Hamilton, L. S. \& Sheppard, D. A. 2001. Transboundary protected areas for peace and co-operation. IUCN, Gland, Switzerland and Cambridge, U. K. Available at www.wcpa.iucn.org.

[12] DEA. Department of Environmental Affairs, South Africa. (2000). Signing of the Lubombo Protocol, Durban, 22 June 2000 - Speech delivered by Minister Helder dos Santos Felix Monteiro Mutela of Mozambique. www.environment.gov.za.

[13] Auclair L., P. Baudot, D. Genin et al. (2011). Patrimony for Resilience: Evidence from the Forest Agdal in the Moroccan High Atlas Mountains. Ecology And Society 16(4). Doi: 10.5751/ES-04429-160424.

[14] Muhweezi A. B.; G. M. Sikoyo, \& M. Chemonges. (2007). Introducing a transboundary ecosystem management approach in the Mount Elgon region: The need for strengthened institutional collaboration Mountain Research And Development 27: 215-219.

[15] Petursson J. G., P. Vedeld, \& J. Kaboggoza. (2011). Transboundary Biodiversity Management: Institutions, Local Stakeholders, and Protected Areas: A Case Study From Mt. Elgon, Uganda and Kenya. Society \& Natural Resources, 24: 1304-1321.

[16] Mugagga F., V. Kakembo, \& M. Buyinza. (2012). Land use changes on the slopes of Mount Elgon and the implications for the occurrence of landslides. CATENA 90: 39-46.

[17] Gorsevski V., E. Kasischke, J. Dempewolf et al. (2012). Analysis of the Impacts of armed conflict on the Eastern Afromontane forest region on the South Sudan - Uganda border using multitemporal Landsat imagery. REMOTE SENSING OF ENVIRONMENT 118: 10-20.

[18] Wachira K., Muluka B., \& Wepundi M. 2001. Mt Elgon conflict: A rapid assessment of the understanding of socio-economic, governance and security factors. Amani papers. UNDP/OCHA.

[19] Lanjou A. Kayitare. A., Rainer, H., Rutagarama E., Sivha, M., Asuma, S., and Kalpers J. 2001 Beyond boundaries: Transboundary natural resource management for Mountain Gorillas in the Virunga-Bwindi Region. Biodiversity support programme. Washington D. C. pp 78.

[20] Thompson L. G.; Brecher H. H.; Mosley-Thompson E.; et al. (2009). Glacier loss on Kilimanjaro continues unabated.
Proceedings of the National Academy of Sciences of the United States of America 106: 19770-19775.

[21] Otte, I., F. Detsch., E. Mwangomo., A. Hemp., T. Appelhans \& T. Nauss (2016) Multidecadal trends and internannual variability of rainfall as observed from Five Lowland Stations at Mt. Kilimanjaro, Tanzania. America Meteorological Society. http://doi: 10.1175/JHM-D-16-0062.s1.

[22] Hemp, A. (2005) Climate change driven forest fires marginalize the impact of ice cap wasting on Kilimanjaro. Global Change Biology 11: http://dx.doi.org/10.1111/j.1365-2486.2005.00968.x.

[23] AWF, IGCP and EcoAdapt. (2012) The implications of global change for Gorilla conservation in the Albertine Rift. A white paper.

[24] Kruger A. C. (2006). Observed trends in daily precipitation indices in South Africa: 1910-2004. International Journal Of Climatology 26: 2275-2285.

[25] Oseni T. O., M. T. Masarirambi. (2011). Effect of climate change on maize (Zea mays) production and food security in Swaziland. American-Eurasian Journal of Agricultural \& Environmental Sciences 11: 385-391.

[26] MERECP [Mt Elgon Regional Conservation Project] project profile, LVBC, (2012). http://www.lvbcom.org/

[27] Simiyu R. R. (2008). Militianisation of Resource Conflicts: The Case of Land-Based Conflict in the Mount Elgon Region of Western Kenya. Institute for Security Studies, South Africa, Johannesburg. 80pp.

[28] Wittmayer J. M. \& B. Buescher. (2010). Conserving Conflict? Transfrontier Conservation, Development Discourses and Local Conflict Between South Africa and Lesotho. Human Ecology 38: 763-773.

[29] Grenfell M. C., W. N. Ellery \& S. E. Grenfell. (2009). Valley morphology and sediment cascades within a wetland system in the KwaZulu-Natal Drakensberg Foothills, Eastern South Africa CATENA 78: 20-35.

[30] Vedeld P, Sjaastad E, Angelsen A, Berg GK (2005). Counting on the Environment: Forest Incomes for the Rural Poor. Environment Department Working Paper, No. 98. World Bank, Washington D. C.

[31] Pelser A. \& L. Letsela. (2012). Mainstreaming sustainability into biodiversity conservation in Lesotho. Environment, Development and Sustainability 14: 45-65.

[32] Naong, M. N. (2011). Learner pregnancy - perceptions on its prevalence and the Child Support Grant (CSG) being the possible cause in South African secondary schools. Journal Of Youth Studies 14: 901-920.

[33] Taylor, R. G., Mileham, L. J., Tindimugaya, C., Majugu, A., Muwanga, A., Nakileza, N., 2006. Recent recession in the Rwenzori Mountains of East Africa due to rising air temperature. Geophysical Research Letters 33, L10402.

[34] Desanker, P. V. 2002. Impact of climate change on life in Africa. Report to the World Life Fund Climate Change Program, Washington. 